\title{
Brief intraoperative heparinization and blood loss in anterior lumbar spine surgery
}

\author{
Emma M. Sim, MB, BS, ${ }^{1}$ Matthew H. Claydon, MB, BS, BMedSci, FRACS, ${ }^{2}$ \\ Rhiannon M. Parker, PhD, ${ }^{3}$ and Gregory M. Malham, MB, ChB, FRACS ${ }^{2}$ \\ ${ }^{1}$ Alfred Hospital; ${ }^{2}$ Epworth Hospital; and ${ }^{3}$ Greg Malham Neurosurgeon, Melbourne, Victoria, Australia
}

OBJECT The anterior approach to the lumbar spine may be associated with iliac artery thrombosis. Intraoperative heparin can be administered to prevent thrombosis; however, there is a concern that this will increase the procedural blood loss. The aim of this study was to examine whether intraoperative heparin can be administered without increasing blood loss in anterior lumbar spine surgery.

METHODS A prospective study of consecutive anterior approaches for lumbar spine surgery was performed between January 2009 and June 2014 by a single vascular surgeon and a single spine surgeon. Patients underwent an anterior lumbar interbody fusion (ALIF) at L4-5 and/or L5-S1, a total disc replacement (TDR) at L4-5 and/or L5-S1, or a hybrid procedure with a TDR at L4-5 and an ALIF at L5-S1. Heparin was administered intravenously when arterial flow to the lower limbs was interrupted during the procedure. Heparin was usually reversed on removal of the causative retraction.

RESULTS The cohort consisted of 188 patients with a mean age of 41.7 years; 96 (51.1\%) were male. Eighty-four patients (44.7\%) had an ALIF, 57 (30.3\%) had a TDR, and 47 (25.0\%) had a hybrid operation with a TDR at L4-5 and an ALIF at L5-S1. One hundred thirty-four patients (71.3\%) underwent a single-level procedure $(26.9 \% \mathrm{~L} 4-5$ and $73.1 \%$ L5-S1) and 54 (28.7\%) underwent a 2-level procedure (L4-5 and L5-S1). Seventy-two patients (38.3\%) received heparinization intraoperatively. Heparin was predominantly administered during hybrid operations (68.1\%), 2-level procedures (70.4\%), and procedures involving the L4-5 level (80.6\%).

There were no intraoperative ischemic vascular complications reported in this series. There was 1 postoperative deep venous thrombosis.

The overall mean estimated blood loss $(\mathrm{EBL})$ for the heparin group $(389.7 \mathrm{ml})$ was significantly higher than for the nonheparin group $(160.5 \mathrm{ml})(p<0.0001)$. However, when all variables were analyzed with multiple linear regression, only the prosthesis used and level treated were found to be significant in blood loss $(p<0.05)$. The highest blood loss occurred in hybrid procedures $(448.1 \mathrm{ml})$, followed by TDR $(302.5 \mathrm{ml})$ and ALIF $(99.7 \mathrm{ml})$. There were statistically significant differences between the EBL during ALIF compared with TDR and hybrid $(p<0.0001)$, but not between TDR and hybrid. The L4-5 level was associated with significantly higher blood loss (384.9 ml) compared with L5-S1 (111.4 ml) ( $p<0.0001)$.

CONCLUSIONS During an anterior exposure for lumbar spine surgery, the administration of heparin does not significantly increase blood loss. The prosthesis used and level treated were found to significantly increase blood loss, with TDR and the L4-5 level having greater blood loss compared with ALIF and L5-S1, respectively. Heparin can be administered safely to help prevent thrombotic intraoperative vascular complications without increasing blood loss.

http://thejns.org/doi/abs/10.3171/2014.12.SPINE14888

KEY WORDS anterior lumbar interbody fusion; blood loss; heparin; total disc replacement; thrombosis; vascular complications

$\mathrm{A}$ NTERIOR approaches to the lumbar spine have substantially increased over the past decade. ${ }^{2}$ The anterior approach is associated with rare but devastating limb-threatening vascular ischemic events. ${ }^{13}$ This is due to the diminution of arterial flow during iliac artery retraction, which is necessary for safe exposure, but can cause arterial obstruction. This can lead to thrombosis or embolic phenomena, with a reported incidence of up to $0.9 \%$. $^{7}$ There have been more than 20 reported cases of common iliac artery thrombosis, predominantly involving

ABBREVIATIONS ACT = activated clotting time; $A L I F=$ anterior lumbar interbody fusion; $A M A V=$ anterior Maverick; DVT = deep venous thrombosis; EBL = estimated blood loss; PLL = posterior longitudinal ligament; rhBMP-2 = recombinant human bone morphogenetic protein-2; TDR = total disc replacement.

SUBMITTED August 27, 2014. ACCEPTED December 30, 2014.

INCLUDE WHEN CITING Published online June 5, 2015; DOI: 10.3171/2014.12.SPINE14888.

DISCLOSURE The authors report no conflict of interest concerning the materials or methods used in this study or the findings specified in this paper. 
the left common iliac artery. $1,3,5,7,8,10-13,16$ To prevent iliac artery thrombosis, heparin can be administered when the retraction causes arterial obstruction. There is concern that this will increase the procedural blood loss. The aim of this study was to examine whether intraoperative heparin can be administered without increasing blood loss in anterior lumbar spine surgery.

\section{Methods}

Between January 2009 and June 2014, we undertook a prospective study of consecutive anterior approaches for lumbar spine surgery performed by a single vascular surgeon (M.C.) and a single spine surgeon (G.M.). Patients underwent an anterior lumbar interbody fusion (ALIF) at L4-5 and/or L5-S1, a total disc replacement (TDR) at L4-5 and/or L5-S1, or a hybrid procedure with a TDR at L4-5 and an ALIF at L5-S1. Indications for surgery were severe discogenic pain, radiculopathy, or Grade 1-2 degenerative or isthmic spondylolisthesis. Exclusion criteria were greater than 2-level disc disease, Grade 3-4 spondylolisthesis, significant iliac artery pathology (heavy calcification, aneurysmal and severe stenosing atherosclerotic disease), morbid obesity (Body Mass Index > 35), previous complex/extensive retroperitoneal surgery, and abdominal/pelvic radiotherapy.

Patients underwent a preoperative abdominal duplex ultrasound scan of the abdominal and iliac major vessels to exclude vascular anomalies, severe atheromatous disease, and calcification. If the duplex scan was poor in quality or a possible abnormality was detected, a CT angiogram was performed.

A right lower transverse muscle-sparing incision with a right-sided retroperitoneal approach was used to access the L5-S1 level. A midline lower abdominal incision with a left-sided retroperitoneal approach was used to access the L4-5 level or multiple levels.

The Omni-Tract (Omni-Tract Surgical) Wishbone Style table-mounted abdominal retractor was used to facilitate access; this was combined with the use of vessel retraction pins driven into the vertebral bodies to restrain iliac vessels. For the L4-5 level, the left common iliac vein was extensively mobilized and the left ascending lumbar vein was usually prophylactically dissected out, ligated in continuity, and divided. This was done to prevent a tearing injury to the common iliac vein due to traction on the ascending lumbar vein, potentially causing significant blood loss.

The Cell Saver 5+ Autologous Blood Recovery System (Haemonetics Corp.) was used in all cases. An independent autotransfusionist measured and recorded the blood loss collected in the cell saver, and an estimate was made of any additional blood loss not collected in the cell saver (such as gauze swabs). A pulse oximeter was placed on the great toes bilaterally; the presence of a signal and its amplitude was monitored as an indicator of significant iliac artery obstruction.

A single dose of unfractionated heparin (heparin sulfate, Baxter) was administered intravenously if the pulse oximeter signal was compromised. After all retractors and vessel retraction pins were in their final position to achieve the required exposure, the vascular surgeon inspected the waveform from each pulse oximeter. If the waveform was severely diminished (i.e., markedly reduced amplitude with flattened waveform) or completely absent (the more common scenario), a dose of $50-75 \mathrm{U} / \mathrm{kg}$ of heparin was administered to achieve therapeutic anticoagulation for at least 30 minutes. We previously found this to be effective in achieving anticoagulation as confirmed by measuring activated clotting time (ACT). After completion of the spinal procedure for that level, the vessel retraction pins were removed and the retractors relaxed. The vascular surgeon re-inspected the oximeter signals to confirm return of the normal signal and waveform before the heparin was reversed with protamine sulfate (Sigma-Aldrich, Inc.). The oximeter signals returned within 1 minute of removing the obstructing retraction. Protamine was not administered if the surgical field was deemed to be dry. Hemostasis was secured with SURGICEL FIBRILLAR (Ethicon, Inc.) and FLOSEAL Hemostatic Matrix (Baxter), if required.

All patients undergoing an ALIF received a single, separate impacted polyetheretherketone (PEEK) cage (Perimeter, Medtronic, Inc.) filled with recombinant human bone morphogenetic protein-2 (rhBMP-2) applied to an absorbable collagen sponge (Infuse; Medtronic, Inc.), per level. An anterior titanium buttress plate (Pyramid, Medtronic, Inc.) fixed the cage. A layer of SURGICEL was then placed over the ALIF construct.

For a TDR, patients received an anterior Maverick device (AMAV; Medtronic, Inc.). The superior and inferior endplates have keels to resist translation. A total discectomy with resection of the posterior anulus was undertaken, and the posterior longitudinal ligament (PLL) was disrupted to allow for mobilization of the disc space. The cartilaginous endplates were removed, and the size of the prosthesis was estimated using trials. A keel cut was made through the superior and inferior endplates, and then the device was inserted with the keels anchoring into the keel cuts as a press fit. A hybrid construct comprised an AMAV at L4-5 and an ALIF at L5-S1. Prior to closure, the pulse status of each foot was assessed to ensure no arterial intervention was required.

Venous thromboembolic prophylaxis was always used intraoperatively with intermittent pneumatic calf compressions and thromboembolic deterrent stockings (T.E.D. anti-embolism stockings, Covidien); and postoperatively with T.E.D. anti-embolism stockings, enoxaparin (Clexane, Sanofi-Aventis), and early mobilization. In patients thought to be at higher risk of deep venous thrombosis (DVT), intermittent pneumatic compression devices were also used postoperatively.

Statistical analysis was carried out using Microsoft Excel (Microsoft Office 2010) and included independent samples t-tests, Fisher's exact tests, and multiple linear regression, with statistical significance measured at $\mathrm{p}<0.05$.

\section{Results}

The cohort consisted of 188 patients who underwent anterior lumbar spine surgery. The mean age was 41.7 years (range $21-73$ years), and 96 patients $(51.1 \%)$ were male. The primary diagnoses were discogenic pain in 90 patients $(47.9 \%)$, degenerative disc disease in $52(27.7 \%)$, 
spondylolisthesis in 24 (12.8\%), herniated nucleus pulposus in $14(7.4 \%)$, stenosis in $5(2.7 \%)$, pseudarthrosis in 2 $(1.1 \%)$, and adjacent-segment disease in $1(0.5 \%)$. Eightyfour patients (44.7\%) had an ALIF, 57 (30.3\%) had an AMAV, and 47 (25.0\%) had a hybrid operation with an AMAV at L4-5 and an ALIF at L5-S1. A total of $242 \mathrm{lev-}$ els were treated with a mean of 1.3 levels treated per patient. One hundred thirty-four patients $(71.3 \%)$ underwent a single-level procedure (26.9\% L4-5 and $73.1 \%$ L5-S1) and $54(28.7 \%)$ underwent a 2-level procedure (L4-5 and L5-S1). Seventy-two patients $(38.3 \%)$ received heparinization intraoperatively. Heparin was predominantly administered during hybrid procedures $(68.1 \% ; 32 / 47)$, followed by AMAV $(49.1 \%$; 28/57) and ALIF (14.3\%; 12/84). The L4-5 level required heparin in $80.6 \%(29 / 36)$ of cases, compared with only 5.1\% (5/98) at L5-S1. Patients received heparin in $25.4 \%$ (34/134) of 1-level procedures and $70.4 \%(38 / 54)$ of 2-level procedures. A summary of patient demographics and treatment information for the heparin and nonheparin groups is provided in Table 1.

In our series, the oximeter signals in all patients returned after release of the retraction. We reported no intraoperative ischemic vascular complications. There were no incidences of heparin-induced thrombocytopenia (HIT) or complications after the administration of protamine. There was 1 postoperative DVT.

Across all patients, there were $62(33.0 \%)$ minor vascular injuries (defined as blood loss $<150 \mathrm{ml}$ from a single vessel injury, usually when an unrecognized branch from the common iliac vein was avulsed when the vein was retracted): 12 injuries (14.3\%) in patients with ALIF, 19 $(33.3 \%)$ in those with AMAV, and $31(66.0 \%)$ in those who underwent hybrid procedures. Overall, there were 20/36 (55.6\%) injuries at L4-5 (6/8 ALIF and 14/28 AMAV) and 10/98 (10.2\%) at L5-S1 (6/71 ALIF and 4/27 AMAV); this difference was statistically significant $(\mathrm{p}=0.0001)$.

The mean estimated blood loss (EBL) for the prosthesis used, number of levels, and levels treated is provided in Table 2. Overall, the mean EBL was $389.7 \mathrm{ml}$ (range $30-1550 \mathrm{ml}$ ) in the heparin group and $160.5 \mathrm{ml}$ (range $10-1400 \mathrm{ml}$ ) in the nonheparin group; this difference was statistically significant $(\mathrm{p}<0.0001)$. Across all variables, the heparin group had greater blood loss than the nonheparin group; however, these differences were not statistically significant $(\mathrm{p}>0.05)$, except in single-level procedures $(\mathrm{p}=0.0001)$. This was because the comparison was predominantly between L4-5 and L5-S1, with $85.3 \%$ of the heparin group having surgery at L4-5 compared with 93.0\% of the nonheparin group having surgery at L5-S1. When comparing the overall (heparin and nonheparin) mean EBL for L4-5 and L5-S1, the L4-5 level was associated with higher blood loss (384.9 ml; range 20-1420 $\mathrm{ml})$ compared with L5-S1 (111.4 ml; range 10-900 ml); this difference was statistically significant $(\mathrm{p}<0.0001)$. The highest blood loss occurred in hybrid procedures (448.1 ml; range 40-1550 ml), followed by AMAV (302.5 $\mathrm{ml}$; range 10-1420 ml), with the lowest being ALIF (99.7 $\mathrm{ml}$; range 10-900 ml). There were statistically significant differences between the mean EBL of ALIF compared with AMAV and hybrid ( $\mathrm{p}<0.0001)$, but not between AMAV and hybrid.
TABLE 1. Patient demographic and treatment information*

\begin{tabular}{|c|c|c|}
\hline Characteristic & Heparin & Nonheparin \\
\hline No. of patients & 72 & 116 \\
\hline Mean age in yrs (SD), range & $\begin{array}{c}38.3(9.3) \\
21-58\end{array}$ & $\begin{array}{c}43.8(11.4) \\
21-73\end{array}$ \\
\hline Female & $38(52.8)$ & $54(46.6)$ \\
\hline Mean BMI (SD), range & $\begin{array}{c}24.9(2.9) \\
19.4-33.1\end{array}$ & $\begin{array}{l}26.3(3.5), \\
18.8-34.6\end{array}$ \\
\hline \multicolumn{3}{|l|}{ Comorbidities } \\
\hline Smoker & $10(13.9)$ & $13(11.2)$ \\
\hline Diabetes & 0 & $2(1.7)$ \\
\hline Hypertension & $3(4.2)$ & $11(9.5)$ \\
\hline Prior lumbar op & $13(18.1)$ & $5(4.3)$ \\
\hline Artificial disc (\% of ops) & $1(7.7)$ & 0 \\
\hline Fusion (\% of ops) & $3(23.1)$ & $2(40.0)$ \\
\hline Laminectomy (\% of ops) & $1(7.7)$ & 0 \\
\hline Microdiscectomy (\% of ops) & $8(61.5)$ & $3(60.0)$ \\
\hline \multicolumn{3}{|l|}{ Primary diagnosis } \\
\hline Adjacent-segment disease & $1(1.4)$ & 0 \\
\hline Degenerative disc disease & $17(23.6)$ & $35(30.2)$ \\
\hline Discogenic pain & $42(58.3)$ & $48(41.4)$ \\
\hline Herniated nucleus pulposus & $6(8.3)$ & $8(6.9)$ \\
\hline Pseudarthrosis & 0 & $2(1.7)$ \\
\hline Spondylolisthesis & $6(8.3)$ & $18(15.5)$ \\
\hline Stenosis & 0 & $5(4.3)$ \\
\hline \multicolumn{3}{|l|}{ Operation } \\
\hline ALIF & $12(16.7)$ & $72(62.1)$ \\
\hline AMAV & $28(38.9)$ & $29(25.0)$ \\
\hline Hybrid & $32(44.4)$ & $15(12.9)$ \\
\hline Levels treated; mean per patient & $110 ; 1.5$ & $132 ; 1.1$ \\
\hline 1 level & $34(47.2)$ & $100(86.2)$ \\
\hline L4-5 (\% of levels) & $29(85.3)$ & $7(7.0)$ \\
\hline L5-S1 (\% of levels) & $5(14.7)$ & $93(93.0)$ \\
\hline 2 levels: L4-5 \& L5-S1 & $38(52.8)$ & $16(13.8)$ \\
\hline \multicolumn{3}{|l|}{ Biologics used } \\
\hline rhBMP-2 & $44(61.1)$ & $87(75.0)$ \\
\hline \multicolumn{3}{|l|}{ Fixation type } \\
\hline Transpedicular bilateral & $6(8.3)$ & $8(6.9)$ \\
\hline
\end{tabular}

BMI = Body Mass Index.

* Unless otherwise indicated, values are expressed as the number (\%).

Multiple linear regression was used to determine whether heparin, prosthesis used, and/or level treated had an effect on blood loss. The number of levels treated was excluded from the model due to multicollinearity with prosthesis used and level. The results of the multiple regression (Table 3 ) show that the prosthesis used and level treated were significant in blood loss $(\mathrm{p}<0.05)$, but heparin use was not $(p=0.5188)$. Heparin was found to be significant in the t-test but not in the multiple regression because the prosthesis type and level had more variance than heparin, which was being averaged over all the variables. This resulted in a higher overall average variance, making the heparin appear significant when the variance 
TABLE 2. Mean EBL for the prosthesis types, number of levels, and levels treated

\begin{tabular}{|c|c|c|c|c|}
\hline \multirow[b]{2}{*}{ Variable } & \multicolumn{3}{|c|}{ Mean EBL in $\mathrm{ml}(\mathrm{SD})$, range } & \multirow[b]{2}{*}{$p$ Value } \\
\hline & Heparin & Nonheparin & Overall & \\
\hline Overall & 389.7 (388.7), 30-1550 & 160.5 (235.5), 10-1400 & & $<0.0001$ \\
\hline ALIF & 140.0 (176.5), 30-680 & 93.0 (134.9), 10-900 & 99.7 (141.3), 10-900 & 0.2891 \\
\hline AMAV & 393.4 (419.3), 30-1420 & 214.7 (306.1), 10-1400 & 302.5 (373.8), 10-1420 & 0.0708 \\
\hline Hybrid & 480.2 (386.3), 40-1550 & 379.7 (308.3), 50-1200 & 448.1 (362.9), 40-1550 & 0.3821 \\
\hline 1 level & 349.0 (403.6), 30-1420 & 129.0 (206.2), 10-1400 & 184.8 (285.1), 10-1420 & 0.0001 \\
\hline L4-5 & 387.1 (425.3), 30-1420 & 375.7 (508.8), 20-1400 & 384.9 (434.9), 20-1420 & 0.9516 \\
\hline L5-S1 & 128.0 (76.9), 50-250 & 110.5 (154.6), 10-900 & 111.4 (151.4), 10-900 & 0.8023 \\
\hline 2 levels: L4-5 \& L5-S1 & 426.2 (376.5), 40-1550 & 357.2 (311.1), 20-1200 & 405.7 (356.9), 20-1550 & 0.5217 \\
\hline
\end{tabular}

* For comparison of heparin versus nonheparin group.

was actually due to the prosthesis type and level, as shown in the regression analysis.

\section{Discussion}

This study provides Class III evidence that the administration of heparin does not affect the blood loss in anterior lumbar spine surgery. Heparin was predominantly administered during hybrid operations (68.1\%), in 2-level procedures $(70.4 \%)$, and for the L4-5 level $(80.6 \%)$.

The overall EBL for the heparin group was significantly higher than for the nonheparin group ( $\mathrm{p}<0.0001)$; however, when all variables were analyzed in the multiple linear regression, only the prosthesis used and level treated were found to be significant in blood loss $(\mathrm{p}<0.05)$.

The highest blood loss occurred in hybrid procedures, followed by AMAV and then ALIF. The blood loss for 2-level procedures was also higher than for single level. AMAV, hybrid, and 2-level procedures are more time consuming and technically complex, requiring greater vessel mobilization and more extensive retroperitoneal dissection. These factors can result in greater blood loss.

An ALIF was found to have significantly less blood loss than an AMAV ( $p<0.0001)$; this difference may be secondary to brisk bleeding from keel cuts during insertion of the AMAV device. The TDR procedure also requires disruption of the PLL to allow for mobilization of the segmental level, which may contribute to the increase in blood loss. Our finding is consistent with a prospective, randomized, controlled, multicenter trial published by Gornet et al., ${ }^{4}$ which showed that patients undergoing AMAV procedures had a statistically significant increase in mean blood loss $(\mathrm{p}<0.001)$ as well as mean operating time $(\mathrm{p}<0.001)$. These differences were thought to be the result of increased technical difficulty of the TDR procedure, keel cuts, and PLL disruption, as discussed above.

The L4-5 level was associated with significantly high-

TABLE 3. Multiple regression analysis of EBL

\begin{tabular}{ll}
\hline Parameter & p Value \\
\hline Heparin & 0.5188 \\
\hline Prosthesis & 0.0006 \\
\hline Level & 0.0232 \\
\hline
\end{tabular}

er blood loss compared with L5-S1 ( $p<0.0001)$. Vascular injuries occur more commonly when exposing the L4-5 level; this was reported by Brau et al., ${ }^{3}$ with $92 \%$ of venous injuries occurring during L4-5 surgery. Many studies similarly report a significantly higher blood loss at

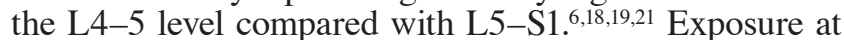
L4-5 requires mobilization of the great vessels, which can lead to inadvertent vascular injuries; in particular, these include left common iliac vein laceration and avulsion of the iliolumbar vein from the common iliac vein. ${ }^{7}$ Exposure of the L5-S1 level is usually performed distal to the aortic and vena cava bifurcations. This requires less mobilization and retraction of the vessels, resulting in fewer vascular injuries. ${ }^{7}$ We report significantly more minor venous injuries at L4-5 $(55.6 \%$; 20/36) compared with L5S1 $(10.2 \% ; 10 / 98)(\mathrm{p}=0.0001)$.

The decision to administer heparin was made after exposure of the target spinal level was complete, prior to commencement of any spinal procedure. Any bleeding encountered up to this point is of vascular origin and should be controlled with mechanical or suture ligation, yielding a dry field before assessment of the oximeter signals. The spinal procedure was not commenced until excellent hemostasis was secured. There were no intraoperative ischemic vascular complications in our series. We have previously reported on the complication rates of performing anterior lumbar spine surgery with rhBMP-2.15

We found no complications related to the administration of heparin and protamine. Heparin is widely used in the perioperative period for the prevention of thromboembolic events. ${ }^{14}$ Increased bleeding is a common complication of heparin use, with a reported incidence of between $0 \%$ and 27\%.16,17 Heparin-induced thrombocytopenia (HIT) is a serious complication of heparin therapy, which is mediated by antibodies to a complex of heparin and platelet factor $4 .{ }^{14}$ It occurs in approximately $0.5 \%$ of medical patients managed with heparin and results in a prothrombotic state that can lead to serious thrombotic events including DVT, pulmonary embolism, myocardial infarction, and stroke. ${ }^{20}$ Protamine is an agent that reverses heparin-induced anticoagulation. ${ }^{20}$ Adverse hemodynamic effects related to protamine administration range from transient hypotension (related to histamine release) to acute pulmonary hypertension. The most serious of these adverse effects, acute pulmonary hypertension, is a 
rare but life-threatening reaction, with 6 cases reported in the literature and an incidence of $0.06 \%$.

Our study prospectively assessed the blood loss caused by intraoperative heparin usage in anterior lumbar spine surgery. An independent autotransfusionist accurately measured intraoperative blood loss. A limitation of the current study is that the anticoagulation effect was not measured individually in the study (for example, by ACT). We used a range of heparin dosages to permit flexibility in the duration of anticoagulation depending on the projected time for completion of the spinal procedure. We also acknowledge that our study is underpowered to examine the effectiveness of heparin in preventing vascular ischemic events. Multiple linear regression was used for statistical analysis rather than a t-test because the former was able to model the relationship of heparin, prosthesis, and level with blood loss. Heparin was found to be significant in the t-test, but not in the multiple regression. The prosthesis type and level had greater variance than heparin, which was being averaged over all the variables; this resulted in heparin appearing significant in the t-test when the variance was actually due to the prosthesis type and level, as shown in the regression analysis. The limitation of using multiple linear regression in our study was that the number of levels treated had to be excluded from the model due to multicollinearity with the prosthesis used and level.

\section{Conclusions}

During anterior exposure for lumbar spine surgery, the administration of heparin does not significantly increase the blood loss. The prosthesis used and level treated were found to significantly increase blood loss, with TDR and the L4-5 level having greater blood loss compared with ALIF and L5-S1, respectively. Heparin can be administered safely to help prevent thrombotic intraoperative vascular complications without increased blood loss.

\section{References}

1. Akinola B, Charnley G: Iliac arterial injury following anterior lumbar surgery: a case report. J Orthop Surg (Hong Kong) 21:369-371, 2013

2. Asha MJ, Choksey MS, Shad A, Roberts P, Imray C: The role of the vascular surgeon in anterior lumbar spine surgery. $\mathbf{B r}$ J Neurosurg 26:499-503, 2012

3. Brau SA, Delamarter RB, Schiffman ML, Williams LA, Watkins RG: Vascular injury during anterior lumbar surgery. Spine J 4:409-412, 2004

4. Gornet MF, Burkus JK, Dryer RF, Peloza JH: Lumbar disc arthroplasty with Maverick disc versus stand-alone interbody fusion: a prospective, randomized, controlled, multicenter investigational device exemption trial. Spine (Phila Pa 1976) 36:E1600-E1611, 2011

5. Hackenberg L, Liljenqvist U, Halm H, Winkelmann W: Occlusion of the left common iliac artery and consecutive thromboembolism of the left popliteal artery following anterior lumbar interbody fusion. J Spinal Disord 14:365-368, 2001

6. Hamdan AD, Malek JY, Schermerhorn ML, Aulivola B, Blattman SB, Pomposelli FB Jr: Vascular injury during anterior exposure of the spine. J Vasc Surg 48:650-654, 2008

7. Inamasu J, Guiot BH: Vascular injury and complication in neurosurgical spine surgery. Acta Neurochir (Wien) 148:375-387, 2006
8. Isley MR, Zhang XF, Smith RC, Cohen MJ: Intraoperative neuromonitoring detects thrombotic occlusion of the left common iliac arterial bifurcation after anterior lumbar interbody fusion: case report. J Spinal Disord Tech 20:104-108, 2007

9. Jerath A, Srinivas C, Vegas A, Brister S: The successful management of severe protamine-induced pulmonary hypertension using inhaled prostacyclin. Anesth Analg 110:365369,2010

10. Khazim R, Boos N, Webb JK: Progressive thrombotic occlusion of the left common iliac artery after anterior lumbar interbody fusion. Eur Spine J 7:239-241, 1998

11. Kim JS, Choi KC, Jung B, Lee SH: Thrombosis of left common iliac artery following anterior lumbar interbody fusion: case report and review of literatures. J Korean Neurosurg Soc 45:249-252, 2009

12. König MA, Leung Y, Jürgens S, MacSweeney S, Boszczyk $\mathrm{BM}$ : The routine intra-operative use of pulse oximetry for monitoring can prevent severe thromboembolic complications in anterior surgery. Eur Spine J 20:2097-2102, 2011

13. Kulkarni SS, Lowery GL, Ross RE, Ravi Sankar K, Lykomitros V: Arterial complications following anterior lumbar interbody fusion: report of eight cases. Eur Spine J 12:48-54, 2003

14. Levy JH, Tanaka KA, Hursting MJ: Reducing thrombotic complications in the perioperative setting: an update on heparin-induced thrombocytopenia. Anesth Analg 105:570582,2007

15. Malham GM, Parker RM, Ellis NJ, Blecher CM, Chow FY, Claydon MH: Anterior lumbar interbody fusion using recombinant human bone morphogenetic protein-2: a prospective study of complications. J Neurosurg Spine 21:851-860, 2014

16. Marsicano J, Mirovsky Y, Remer S, Bloom N, Neuwirth M: Thrombotic occlusion of the left common iliac artery after an anterior retroperitoneal approach to the lumbar spine. Spine (Phila Pa 1976) 19:357-359, 1994

17. Pachter HL, Riles TS: Low dose heparin: bleeding and wound complications in the surgical patient. A prospective randomized study. Ann Surg 186:669-674, 1977

18. Sinigaglia R, Bundy A, Costantini S, Nena U, Finocchiaro F, Monterumici DA: Comparison of single-level L4-L5 versus L5-S1 lumbar disc replacement: results and prognostic factors. Eur Spine J 18 (Suppl 1):52-63, 2009

19. Tiusanen H, Seitsalo S, Osterman K, Soini J: Anterior interbody lumbar fusion in severe low back pain. Clin Orthop Relat Res (324):153-163, 1996

20. Weitz JI: Blood coagulation and anticoagulant, fibrinolytic and antiplatelet drugs, in Brunton LL (ed): Goodman \& Gilman's The Pharmacological Basis of Therapeutics, ed 12. New York: McGraw-Hill, 2011, pp 858-859

21. Wood KB, Devine J, Fischer D, Dettori JR, Janssen M: Vascular injury in elective anterior lumbosacral surgery. Spine (Phila Pa 1976) 35 (9 Suppl):S66-S75, 2010

\section{Author Contributions}

Conception and design: Malham, Claydon. Acquisition of data: Malham, Sim, Claydon. Analysis and interpretation of data: all authors. Drafting the article: all authors. Critically revising the article: all authors. Reviewed submitted version of manuscript: all authors. Approved the final version of the manuscript on behalf of all authors: Malham. Statistical analysis: Parker. Study supervision: Claydon.

\section{Correspondence}

Gregory M. Malham, 517 St. Kilda Rd., Ste. 2, Level 1, Melbourne VIC 3004, Australia. email: gmalham@bigpond.net.au. 